www.revistadyo.com

\title{
Enfoque estratégico para la identificación de cuellos de botella en entornos de fabri- cación contra pedido y plantas tipo V: estudio de caso de DBR.
}

\author{
Lizarralde A, Apaolaza U, Mediavilla M
}

Recibido: 26 de Julio de 2018 / Aceptado: 10 de Octubre de 2018

\begin{abstract}
Resumen
Uno de los principales elementos de la teoría de las limitaciones es su método de gestión de la producción Drum-Buffer-Rope (DBR) que controla el lanzamiento de trabajos al sistema. La secuencia en la que se lanzan los trabajos al sistema está determinada por la programación del Drum. En la literatura se observa que está demostrada la validez del método para gestionar la producción, pero la mayoría se centran en estudios analíticos y no tienen en cuenta casos reales de producciones bajo pedido y plantas v. En este estudio exponemos un proceso sistemático para la implementación de los dos primeros pasos de TOC en sistemas productivos. Lo hacemos desde una perspectiva estratégica, esto es, el recurso que controla el lanzamiento y ritmos de producción debe ser una decisión gerencial.
\end{abstract}

\section{Palabras clave}

Drum-Buffer-Rope; Teoría de las Limitaciones; decisión estratégica.

\section{Introducción}

La competencia existente en el mercado ha inducido una evolución en las operaciones industriales, con un constante crecimiento del número de referencias en catálogo y la reducción, tanto de los tamaños de serie como de la vida del producto en el mercado (De La Calle et al. 2017; Stevenson et al. 2005; Holweg \& Pil 2004). Estas circunstancias hacen de la gestión de las operaciones industriales un elemento diferencial, el cual diferencia a la empresa que es excelente desde el punto de vista del cliente y la que no lo es (Gupta $\&$ Boyd 2008). En este paradigma han surgido diferentes filosofías para dar respuesta a dicha problemática, tales como la Teoría de la Limitaciones (TOC), Lean Manufacturing, Quick-Response-Manufacturing (QRM), etc.

Este trabajo presenta el proceso de implantación de la filosofía TOC en una empresa manufacturera del sector aeronáutico, realizado con el objetivo de mejorar los plazos de

\footnotetext{
A Aitor Lizarralde *

alizarralde@mondragon.edu

https://orcid.org/0000-0002-1390-9817

Unai Apaolaza *

uapaolaza@mondragon.edu

https://orcid.org/0000-0003-3257-9291

Miguel Mediavilla *

miguel.mediavilla@operations.es

https://orcid.org/0000-0003-2471-0472

*Dpto. de Mecánica y Producción Industrial. Mondragon Unibertsitatea. Loramendi 420500 Arrasate-Mondragón Gipuzkoa.
}

entrega mediante la creación de un sistema de gestión de la producción basado en la metodología Drum-Buffer Rope (DBR) de TOC.

El objetivo de esta comunicación es presentar las implicaciones de los dos primeros pasos de la metodología TOC: seleccionar y explotar el cuello de botella. Usualmente es una decisión que la literatura ha resuelto de manera táctica, mediante la identificación de la carga / capacidad en los elementos del sistema productivo. Sin embargo, hay autores que recientemente han sugerido la necesidad de aportaciones adicionales a este planteamiento (Naor et al. 2013).

El artículo se compone de una introducción a los conceptos básicos de TOC y DBR, para luego presentar un capítulo de metodología, donde presentamos el acercamiento de investigación en acción (Action Research). A continuación, presentamos el estudio de caso, la participación de los investigadores y los resultados obtenidos. Finalizamos con las conclusiones y líneas futuras de investigación.

\section{TOC y la metodología Drum Buffer Rope (DBR)}

En empresas con productos altamente personalizados y que presentan dificultades para estimar anticipadamente los tiempos de proceso en sus rutas, la eficacia de la aplicación de TOC está demostrada (Stevenson, Hendry \& Kingsman, 2005). Esto se debe al hecho de que en la gestión de la producción en la TOC sólo requiere la exactitud de los datos en el Cuello de Botella (CB) para controlar el rendimiento de la planta (Gupta, Snyder \& Snyder, 2009). 
Para gestionar la producción de un entorno fabril, el enfoque TOC de Goldratt (Goldratt \& Cox 2005) propone la metodología DBR (también llamada tambor-pulmón-cuerda). El tambor representa el ritmo productivo del sistema, que ha de estar marcado por la capacidad del CB. El pulmón es una protección de stock medido en tiempo o número de piezas lanzadas para que lleguen con antelación al $\mathrm{CB}$, de modo que lo resguarden de cualquier incidencia derivada de procesos anteriores. El propósito de los buffers de envío es que una vez las piezas se terminen de procesar en el CB, éstas sean procesadas lo antes posible (Goldratt \& Fox 1986). La cuerda es el sistema de información que une el programa del CB a primeras operaciones y a los acopios de materiales. Usualmente el resto de recursos se programan mediante las prioridades derivadas de las necesidades del $\mathrm{CB}$, lo que proporciona una gran simplicidad de gestión del sistema productivo y de planificación (Goldratt 1990).

La idea básica de la TOC es que todo sistema cuenta con al menos una limitación o CB, y que, en base a la aplicación de una serie de reglas, centradas en los $\mathrm{CB}$, es posible optimizar el resultado del sistema.

\section{Metodología de Investigación}

Las singularidades de la investigación en gestión, tales como la doble dependencia de los elementos físicos y humanos de una organización, a menudo impiden que el investigador tome el control de los acontecimientos (Drejer, Blackmon \& Voss, 2000). Por ello, y dado que el propósito de esta investigación es conocer en detalle el proceso de implantación de la metodología DBR en una planta productiva, la investigación a través de los Estudios de Casos (EC) es adecuada: una investigación con profundidad, sobre datos recogidos en un periodo de tiempo determinado, de una o más empresas, o grupos dentro de las empresas, con el objetivo de generar un análisis del contexto y de los procesos implicados en el fenómeno objeto de estudio (Hartle 1994).

Los EC proporcionan acceso directo a la información, logrando un profundo conocimiento del contexto analizado (Rowley 2002; Wacker 1998). Cuando la investigación coincide con la acción en la que participa el investigador, los estudios de casos pueden realizarse mediante una forma específica llamada "Investigación en Acción" (Lewin 1946; Lewin, Lippitt \& White, 1939), En este contexto, el investigador no es un observador neutral (Easterby-Smith, Thorpe \& Lowe, 2002; Gummesson, 2000), sino un participante que además de tomar parte en la implantación busca evaluar una determinada técnica de intervención (Benbasat et al. 1987), por lo que trata de influir en el desarrollo del proceso, interviene deliberadamente en el contexto de la investigación con objeto de tratar de conseguir mejoras concretas en los resultados, o para conducirlo de acuerdo con su interpretación de la situación en cada momento (Platts et al. 1998).

\section{Caso en industria y aplicación del proceso sistemático}

El estudio de caso se ha desarrollado en una empresa de mecanizado de precisión del sector aeronáutico ubicada en el País Vasco. En el pasado su ventaja competitiva se había centrado en una calidad de producto excepcional. En los últimos años, sin embargo, el hecho de suministrar sus productos directamente a los montajes de aviones ha hecho que la fiabilidad de entregas (cumplir fechas, además de ser capaz de reducir el plazo de entrega) haya adquirido una importancia vital.

La empresa fabrica usualmente pequeños lotes de productos bajo pedido (make-to-order). La demanda es ciertamente estable, ya que se conocen con antelación los programas de entrega para el propio montaje del avión. Por otro lado, la organización fabril de planta es funcional (job-shop) y se considera una planta "V", es decir, partiendo de pocas materias primas produce muchos productos terminados

La empresa contactó con los investigadores con el objetivo de desarrollar un acercamiento innovador que le permitiera mejorar su capacidad de cumplir con las fechas de entrega a sus clientes con mayor fiabilidad, así como acortar sus plazos de entrega. Para ello, los investigadores aplicaron los cinco pasos de la metodología TOC. Su aplicación en tipologías de fabricación MTO y plantas V es compleja, ya que es difícil conseguir utilizaciones de máquina altas y niveles de servicio altos (Darlington et al. 2015), y no hay evidencias empíricas en la literatura que proporcionen perspectivas prácticas que abarquen toda la complejidad de sistemas productivos reales (Naor et al. 2013).

Si bien el proyecto de investigación abarca toda la implementación de TOC, el propósito de este artículo es profundizar en el proceso de resolución para los dos primeros pasos: Identificar y explotar el CB.

Los investigadores han desarrollado un proceso sistemático (tabla 1) para la implementación de los dos primeros pasos de TOC en sistemas productivos make-to-order (MTO), con objeto de asegurar la máxima eficiencia en su aplicación.

El trabajo de campo realizado por los investigadores se prolongó de enero a junio de 2017.

\subsection{Definición del "D" del DBR}

La metodología DBR para sistemas productivos se compone de tres variables, si bien el foco de esta investigación se centra en la profundización de los dos primeros pasos (Goldratt 1990) que corresponden al Drum (o tambor en español): (1) Identificar las limitaciones del sistema, sean físicas (materiales, máquinas, personas, nivel de demanda, etc.) o de gestión. Los sistemas productivos suelen tener más 
limitaciones de gestión que físicas (Goldratt 1990). (2) Decidir cómo explotar las limitaciones del sistema, ya que una vez localizados aquellos recursos que limitan el rendimiento global del sistema, éstos deben ser explotados al máximo para aprovechar toda su capacidad.

Si bien la literatura que discute la aplicación de TOC es abundante, existen pocas evidencias referente al estudio de estos dos primeros pasos en sistemas productivos reales
(Gupta \& Boyd 2008), sólo habiendo algunos acercamientos basado en simulaciones y el análisis carga/capacidad del sistema. Los investigadores han desarrollado un proceso sistemático (tabla 1) para la implementación de los dos primeros pasos de TOC en sistemas productivos make-to-order (MTO), con objeto de asegurar la máxima eficiencia en su aplicación:
Tabla 1 Proceso para identificar y explotar el cuello de botella

\begin{tabular}{lll}
\multicolumn{1}{c}{ Etapa } & \multicolumn{1}{c}{ Proceso } & \multicolumn{1}{c}{ Propósito } \\
\hline Etapa 1: Análisis del sistema & $\begin{array}{l}\text { Análisis del proceso productivo, capaci- } \\
\text { dades de centros, política de lotes, indica- } \\
\text { dores y rutas de piezas. }\end{array}$ & $\begin{array}{l}\text { Conocimiento de las políticas, reglas e indi- } \\
\text { cadores en la gestión de la producción. }\end{array}$ \\
Etapa 2: Estudio carga/capacidad & $\begin{array}{l}\text { Comparar la demanda de un periodo con la } \\
\text { capacidad de cada centro en dicho periodo. }\end{array}$ & Identificar limitaciones del sistema. \\
Etapa 3: Decisión estratégica de la & $\begin{array}{l}\text { Reuniones con la dirección para decidir la } \\
\text { limitación del sistema }\end{array}$ & Decisión estratégica del Cuello de Botella. \\
limitación & $\begin{array}{l}\text { Definir con planificación y producción las } \\
\text { políticas de planificación del CB }\end{array}$ & $\begin{array}{l}\text { Diseñar políticas, reglas e indicadores para } \\
\text { sistema }\end{array}$ \\
\hline
\end{tabular}

\subsubsection{Etapa 1: Análisis del sistema}

La primera etapa se centra en analizar los diferentes procesos de la empresa unidos al ciclo pedido - entrega, para identificar las políticas, reglas e indicadores que la rigen. En el caso estudiado, el objetivo principal de la empresa era el equilibrar la capacidad productiva de todas sus secciones, para lo que se planificaban todos los centros con una herramienta de planificación a capacidad finita y medían la productividad de cada una de las secciones. Ello hacía que la empresa tuviera una clara orientación a la saturación de todos sus recursos y unos niveles de inventario en curso muy altos. Dado que las plantas "V" se caracterizan por un bajo nivel de utilización de recursos, para lograr el equilibrado de secciones los responsables debían a lanzar muchas órdenes de trabajo, saturando así las máquinas.

El resultado de lo desarrollado en la etapa 1 se resume en la tabla 2.

Tabla 2 Síntesis de la situación inicial

\begin{tabular}{ll}
\hline \multicolumn{1}{c}{ Visión General } & \multicolumn{1}{c}{ Detalle } \\
\hline & \\
Bajo nivel de servicio (Objetivo: $90 \%$; realidad: $75 \%)$ & Lotes de fabricación muy grandes (alineado con la medida piezas/hora). \\
Alto lead time (6 semanas). & Prioridades poco claras en planta. \\
Alto trabajo en curso-Work in Progress (WIP). & Ninguna herramienta de planificación ni control en planta. \\
Indicador principal: productividad por recurso. & Operarios centrados en aumentar la productividad de su centro. \\
& Cuellos de botella "móviles" en la planta. \\
& Imposibilidad de respetar FIFO.
\end{tabular}

\subsubsection{Etapa 2: Estudio de carga/capacidad}

El propósito de esta fase es la identificación de las restricciones reales del sistema. Para ello se realiza un análisis de la capacidad disponible de cada recurso y la capacidad requerida por la demanda en un horizonte determinado. Tanto los datos de demanda a futuro como los datos históricos son de utilidad para este fin.

En el caso estudiado, el resultado de dicho análisis reveló que la limitación del sistema era la fase de montaje y ajuste de piezas, demostrando que la empresa no era capaz de producir más de lo que podía procesar esta sección.

\subsubsection{Decisión estratégica de la limitación}

Desde una perspectiva operativa, este paso se puede hacer mediante un estudio de carga versus capacidad de cada centro, identificando como limitación del sistema el recurso con mayor nivel de saturación. Sin embargo, nuestro proceso no sólo abarca la identificación de la limitación del sistema de un modo operativo (etapa 2), sino que eleva su importancia: la selección de la limitación debe ser una decisión estratégica de la empresa (Ronen \& Pass 2008; Goldratt 1990; Cox et al. 2003). La dirección de la empresa debe elegir cuál es su limitación, y en el caso de estudio se optó por el recurso que cumplía las siguientes condiciones: 
- El recurso es limitado en capacidad: es difícil elevar la capacidad al recurso seleccionado, bien porque requiere de una gran inversión o es muy difícil de encontrar alternativas fuera.

- El recurso es una fortaleza en habilidad: el recurso seleccionado debe ser un punto fuerte en habilidad para la empresa, en otras palabras, es el principal conocimiento de la organización y posiblemente su razón de ser.

- Su carga se mantiene estable ante cambios de mix de producto.

- Recurso común para la gran mayoría de productos.

Después de diferentes entrevistas semiestructuradas, sesiones grupales de discusión y sesiones de convergencia con la dirección de la empresa, el equipo directivo decidió que la restricción del sistema fuera la sección de Tornos Grandes. Esto implicó elevar la capacidad de la sección de montaje a través de una nueva incorporación y un cambio de funciones de otro recurso ya existente.

\subsubsection{Decidir cómo explotar el Sistema}

En esta etapa se definen los criterios con los que se va a planificar la carga de trabajo en el CB. Se definen tanto los tamaños de lote de fabricación como los totes de transferencia, buscando maximizar el flujo de materiales.

El objetivo buscado es la reducción del lote de transferencia, definido como la cantidad de unidades que pasan a la siguiente operación, ya que si éste se reduce y se mantiene en la ruta de la orden de fabricación, se necesita menos tiempo de procesamiento total en el sistema y se logra disminuir el inventario en curso.
Otro de los aspectos fundamentales a la hora de planificar el CB es tener en cuenta otros recursos críticos del sistema (Gupta \& Boyd 2008). Se puede dar el caso de que un recurso no $\mathrm{CB}$ pase a ser una limitación por la forma de planificar el $\mathrm{CB}$, esto es, pese a contar con margen de capacidad en el resto de operaciones, una mala planificación puede llegar a generar problemas de capacidad en forma de picos de carga no asimilables en dichas operaciones.

En el caso estudiado, dos recursos (planeadora y el centro de mecanizado 07) eran dos puntos a tener en cuenta en la planificación del CB, ya que no eran capaces de procesar más de una cantidad determinada de ciertas piezas a la semana. Consecuentemente, el programa del CB (figura 1) se planificaba semanalmente saturando su capacidad y respetando los límites de esos tipos de pieza especial que podían procesar estos dos recursos. El resto de recursos tenían margen de capacidad suficiente.

\subsection{Diseño de la solución}

El sistema DBR se construyó tomando los tornos grandes como CB del sistema (ver detalles en figura 1): (*) DRUM (tambor): Programa del CB en base a la fecha entrega, limitaciones de otros recursos (C07 y Planeadora) y la duración de los diferentes buffers. (*)BUFFER (pulmón): se crearon tanto los buffers de CB como los de envío, teniendo en cuenta las duraciones de las operaciones de antes y después de la operación del CB respectivamente. La función del buffer de $\mathrm{CB}$ es la de empezar las primeras operaciones con el tiempo suficiente para que el material llegue al CB. El buffer de envío es el tiempo en el que somos capaces de llevar el material procesado en el $\mathrm{CB}$ a producto terminado. (*) ROPE (cuerda): La entrada y salida de trabajos en el CB deben estar equilibradas. Por tanto, el resto de operaciones se deben subordinar al CB. La cuerda es la responsable de proporcionar la señal de cuanto trabajo meter en cada momento al sistema. El buffer nos proporciona el cuándo.

Figura 1 Diseño de la solución en la empresa del caso

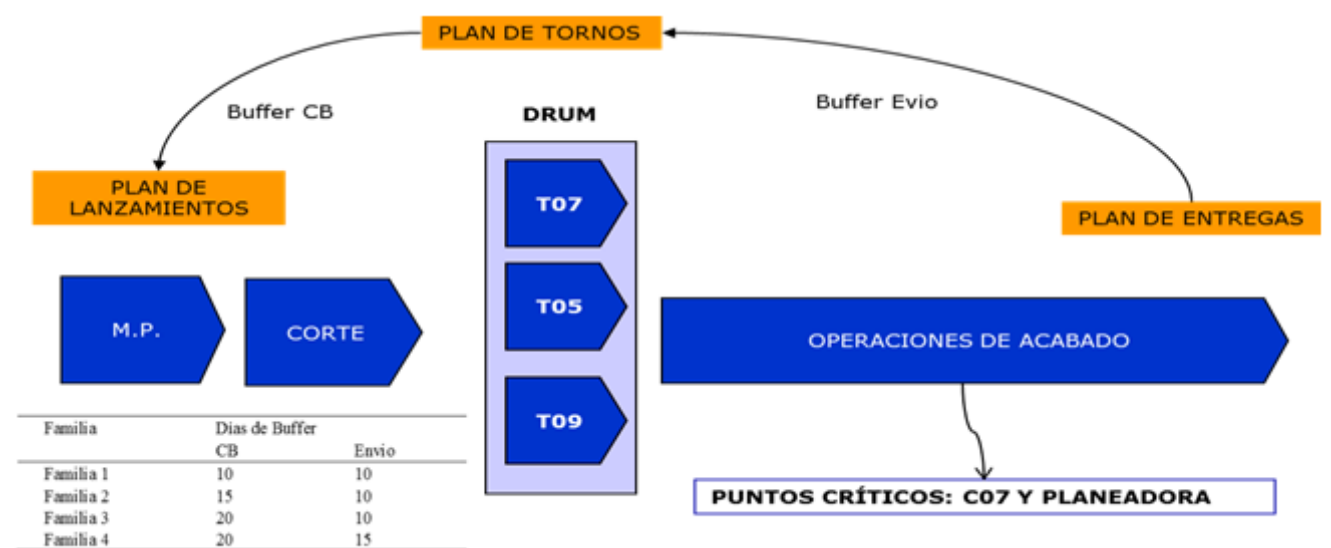




\subsection{Resultados}

Los principales resultados logrados en la implantación son el aumento del nivel de servicio, reducción del periodo de maduración (lead time) de fabricación y reducción del stock en curso (WIP), aumentando consecuentemente la facturación media mensual, sin apenas aumentar la capacidad. A continuación se detallan estos aspectos:

- Mejora del nivel de servicio: El nivel de servicio pasó del $75 \%$ al $95 \%$ de cumplimiento de pedidos en plazo y cantidad, dado que los retrasos debidos a causas de fabricación se minimizaron, aumentando consecuentemente la facturación media mensual. Basándose en la nueva metodología, prácticamente todas las órdenes comprometidas se completaron dentro del periodo establecido, reduciendo dramáticamente los retrasos debidos a causas de fabricación, y requiriendo sólo algunas horas extra.

- Reducción del lead time de fabricación: El periodo de maduración de fabricación bajó de seis a cuatro semanas. Teniendo en cuenta que el lead time de fabricación depende del tiempo necesario para procesar el inventario en curso, al haber descendido este último considerablemente, el lead time también se redujo en un $35 \%$, pasando de 45 días con el sistema antiguo a 30 con la nueva sistemática de trabajo.

- Reducción del nivel de inventario: el modelo anterior fomentaba una alta saturación de todas las operaciones, lo que conllevaba altos niveles de WIP. Al restringir la entrada de trabajos al sistema en base a la capacidad del $\mathrm{CB}$ se produjo como resultado una reducción del $30 \%$ del inventario en curso.

\section{Conclusiones y Líneas futuras de in- vestigación}

TOC y DBR suponen una ruptura con la forma de pensar tradicional en las operaciones. Sin embargo, su aplicación no es simple y requiere de una comprensión precisa de sus principios.

Nuestro proceso sistemático ayuda a aplicar DBR exitosamente desde una perspectiva estratégica, superando la perspectiva dominante centrada en aspectos operativos de carga/capacidad.

Del presente trabajo se concluye que hay dos componentes esenciales necesarios en una implementación: la adaptación del método al contexto y la aceptación del método dentro de la organización. La adaptación se basa en la comprensión del contexto y del método, de modo que se cree un modelo adecuado. La aceptación, en cambio, está relacionada con otros factores como la cultura y la madurez de la empresa, su voluntad de cambio y el compromiso respecto al método y al rigor requerido por éste. La dirección de la empresa tiene que estar alineada con la solución definida e impulsar a la organización para conseguir los resultados planteados.

Es importante destacar que, siendo el factor que limita la capacidad total del sistema, la selección de CB es esencial. Decidir sobre el CB adecuado va más allá de la identificación: es una decisión estratégica que puede implicar medidas adicionales para ajustar la capacidad en toda la organización. La idea subyacente es evitar los cambios de CB tomando medidas en el resto de recursos del sistema. De esta manera, el CB permanecerá sin cambios, manteniéndose así las condiciones adecuadas para la gestión DBR.

Por lo tanto, este estudio confirma la proposición de que la metodología DBR se puede aplicar con éxito en sistemas de distribución en plantas funcionales tipo V y entornos MTO.

El desarrollo de estudios de casos adicionales en diferentes organizaciones es de especial interés para lograr una comprensión profunda de los factores subyacentes en estos contextos, especialmente en empresas cuya tipología de producto es de volumen bajo-medio y variedad de media-alta.

Por ello, con objeto de reforzar la validez de esta metodología, invitamos a otros autores a seguir investigando mediante casos empíricos, en la puesta en práctica de TOC y DBR en sistemas productivos reales pertenecientes a otros procesos y sectores.

\section{Bibliografía}

Benbasat, I., Goldstein, D.K. \& Mead, M., 1987. The Case Research Strategy in Studies of Information Systems. MIS Quarterly, 11(3), pp.369-386.

Cox, J.F., Blackstone, J.H. \& Schleier, J.G., 2003. Managing Operations: A Focus on Excellence. North River Press, Great Barrington.

Darlington, J. et al., 2015. Design and implementation of a Drum-Buffer-Rope pull-system. Production Planning and Control, 26(6).

Drejer, A., Blackmon, K. \& Voss, C., 2000. Worlds apart? - a look at the operations management area in the US, UK and Scandinavia. Scandinavian Journal of Management, 16(1), pp.45-66.

Easterby-Smith, M., Thorpe, R. \& Lowe, A., 2002. Management Research: An Introduction 2nd ed., London: Sage Publications.

Goldratt, E. \& Cox, J., 2005. La Meta Un proceso de mejora continua, Ediciones Castillo. 
Goldratt, E.M., 1990. What is this thing called Theory of Constraints, and how should it be implemented?, New York: North River Press.

Goldratt, E.M. \& Fox, R.E., 1986. The Race,

Gummesson, E., 2000. Qualitative Methods in Management Research, Sage Publications.

Gupta, M., Snyder, \& D. \& Snyder, D., 2009. Comparing TOC with MRP and JIT: a literature review. International Journal of Production Research, 47(13), pp.3705-3739.

Gupta, M.C. \& Boyd, L.H., 2008. Theory of constraints: a theory for operations management. International Journal of Operations \& Production Management, 28(10), pp.991-1012.

Hartle, J., 1994. Case studies in organizational research, London: Sage publications.

Holweg, M. \& Pil, F.K., 2004. The second century: reconnecting customer and value chain through build-to-order: moving beyond mass and lean production in the auto industry, MIT Press.

De La Calle, A., Grus, M.E. \& Álvarez, E., 2017. Value creation through demand and supply chains: Evidences from Spanish companies. Direccion y Organizacion, 61, pp.4-11. Available at: http://www.ww.revistadyo. com/index.php/dyo/article/view/500 [Accessed July 19, 2018].
Lewin, K., 1946. Action Research and Minority Problems. Journal of Social Issues, 2(4), pp.34-46.

Lewin, K., Lippitt, R. \& White, R.K., 1939. Patterns of Aggressive Behavior in Experimentally Created "Social Climates." The Journal of Social Psychology, 10(2), pp.269-299.

Naor, M., Bernardes, E.S. \& Coman, A., 2013. Theory of constraints: Is it a theory and a good one? International Journal of Production Research, 51(2), pp.542-554.

Platts, K.W. et al., 1998. Testing manufacturing strategy formulation processes. International Journal of Production Economics, 56, pp.517-523.

Ronen, B. \& Pass, S., 2008. Focused Operations Management: Doing More with Existing Resources,

Rowley, J., 2002. Using Case Studies in Research Hill College of Higher. Management research news, 25, pp.1627.

Stevenson, M., Hendry, L.C. \& Kingsman, B.G., 2005. A review of production planning and control: the applicability of key concepts to the make-to-order industry. International Journal of Production Research, 43(5), pp.869-898.

Wacker, J.G., 1998. A definition of theory: research guidelines for different theory-building research methods in operations management. Journal of Operations Management, 16(4), pp.361-385. 